$$
347.625
$$

\title{
Dos Deveres Comuns a Ambos os Cônjuges.
}

\author{
Washington de Barros Monteiro \\ Catedrático de Direito Civil da Faculdade de \\ Direito da Universidade de São Paulo.
}

\begin{abstract}
SUMÁrio: 1. Da importância do casamento. 2. Dos efeitos que dêle resultam. 3. Dos deveres comuns a ambos os cônjuges. 4. Do dever de fidelidiade recíproca. 5. Violação do dever. 6. Caracterização do adultério. 7. Diferença de tratamento entre o adultério do marido e o da mulher. 8. Colocação do problema sob o ângulo psicológico. 9. Vigência do dever de fidelidade. 10. Vida em comum, no domicílio conjugal. 11. Debitum conjugale. 12. Mútua assistência. 13. Sustento, guarda e educação dos filhos.
\end{abstract}

14. Conclusão.

1. O casamento é o instituto fundamental de todo o direito de família. $\mathrm{E}$ o eixo em tôrno do qual gravita todo o sistema jurídico familiar. Na frase de Alberto G. Spota (Tratado de Derecho Civil, 3/5), é a raiz e o comêço de uma instituição básica da sociedade, a família legítima, cujo conceito nêle descansa, como pressuposto lógico-jurídico.

Já houve quem dissesse que se na terra há uma expressão divina, é o casamento. Não há, todavia, instituição a respeito da qual mais variem as opiniões, pois ao matrimônio já se atribuíram múltiplas denominações: um abrigo, um refúgio, uma coroa de glórias, um estado de servidão e até um divertimento.

Recordo-me de livro, lido em minha juventude, o Delator, de Liam O'FlaherTy, em que um dos personagens afirma, a certa altura, que o casamento é instituição 
puramente capitalista, que tem por fim proteger a propriedade, para que os filhos legítimos possam herdar de seus pais.

Creio, no entanto, com as Novelas, que nihil in rebus mortalium perinde venerandum est ataque matrimonium, ou, em vernáculo, nenhuma coisa mortal é mais veneranda do que o casamento.

2. Essa união é o ponto de partida de tôda a vida social. Como é óbvio, dela decorrem vários e importantes efeitos, quer em relação aos cônjuges, quer em relação aos filhos, quer em relação a terceiros. Referentemente aos cônjuges, muitos efeitos são pessoais, enquanto outros dizem respeito aos respectivos bens. São tantos êsses efeitos que nenhum jurista, até agora, tentou esgotar-lhes a enumeração, temoroso, talvez, de alguma omissão.

Pela ordem de precedência, o primeiro efeito é a criação da família legítima. Ou como se expressa o artigo 229 do Código Civil: "criando a família legítima, o casamento legitima os filhos comuns, antes dêle nascidos ou concebidos" (artigos 352 a 354).

Eis aí, de fato, o precípuo objetivo do legislador, a criação da família legítima, imprimindo-lhe ritmo de conveniência, ordem e economia. Através dessa criação, o legislador disciplina a união dos sexos, depura os sentimentos, reprime as paixões, provê sôbre a situação da prole e circunda de respeito a família que se constitui sob a sua égide.

Como acentua CLóvis (Código Civil, 2/105), e de quem hauri êsses conceitos, aí está a intervenção do direito, na sua função orgânica e santificadora, a diferençar a família legítima da natural, a família legítima de outros agrupamentos efêmeros e inconsistentes, que as necessidades fisiológicas promovem e dissolvem.

A união entre o homem e a mulher, sem casamento, acrescenta De RugGiero (Instituições de Direito Civil, 
2/52), é reprovada pelo direito; degenera em concubinato, quando porventura não seja adultério ou incesto.

Entretanto, conforme sublinha CÂNDIDo DE OLIveIRa (Manual do Código Civil, de Paulo de LAcerda, pág. 265), a construção do artigo 229 não prima pela elegância: começa com um particípio, e mostra-se ocioso em sua segunda parte, pois a legitimação por subseqüente matrimônio é regulada, em seguida, quase nos mesmos têrmos, pelo artigo 353 .

Justificam-se, porém, tais disposições. Por um princípio de eqüidade, o casamento retroage e, fazendo cessar o estado de união ilegítima, desfaz, ao mesmo tempo, a posição ilegítima dos filhos havidos anteriormente, ou apenas concebidos.

3. 'Os deveres comuns a ambos os cônjuges vêm previstos no artigo 231: fidelidade recíproca, vida em comum no domicílio conjugal, mútua assistência. sustento, guarda e educação dos filhos.

Há quem objete quanto à expressão deveres, que seria inadequada, em se tratando de preceito de lei positiva. Contudo, essa era a expressão que figurava no primitivo projeto de Cuớvis (artigo 270), vindo a subsistir em tôda a sua tramitação, até a respectiva redação final. Mourlon (Répétitions Écrites sur le Code Civil, 12." ed., $1 .^{\circ}$ vol. pág. 395 ), opta pela palavra obrigação, que melhor se coaduna com a linguagem jurídica.

Evidentemente, a lei não pode abranger todos os deveres. Limita-se ela aos mais importantes, havidos como, essenciais pela ordem pública e pelo interêsse social.

$\mathrm{Na}$ respectiva discriminação, atém-se o legislador a um mínimo de exortações. Mas, fora de seu campo de ação, ocorrem ainda outros numerosos deveres morais, imprescindíveis à boa harmonia conjugal, à felicidade doméstica e à paz familiar, como o mútuo amor, a con- 
fiança e o respeito recíproco, além da paciência e da compreensão, que dependem de cada cônjuge individualmente, de sua educação, cultura, sensibilidade e temperamento.

4. O primeiro e o mais importante dos deveres recíprocos dos cônjuges é o de fidelidade. No dizer de Clớvis, esta é a natural expressão da monogamia. A fidelidade não constitui tão-sòmente um dever moral. Ela é exigida pelo direito, em nome dos superiores interêsses da sociedade.

A infração dêsse dever configura adultério, que é, no dizer de Beudant (L'Etat et la Capacité des Personnes, $1 / 427$ ), o fato que fere e perturba de modo mais profundo a vida da família.

De fato, grandes são os deveres que o estado de casado impõe. Importa, por isso, que o compromisso que dêle decorre seja sagrado e inviolável.

Uma vez cometido adultério, não há mais estima, não há mais confiança, não há mais ternura e a união entre os cônjuges se acha comprometida em tôda a sua estrutura.

Com razão afirmou Cronin (Pelos caminhos de minha vida, pág. 282), que "a pior ofensa que se pode fazer contra o casamento, o rochedo contra o qual a felicidade da família em geral se despedaça, é a infidelidade". O adultério. do marido ou da mulher, representa, sem dúvida, a mais nítida manifestação de falência da moral familiar (G. L. Duprat, Le Lien Familial, pág. 138).

Em meu livro Direito de Família. 8. ${ }^{\mathrm{a}}$ ed., pág. 111, tive ocasião de desprezar, como imorais e anti-sociais, conceitos como o de VARGaS Vila (Los Estetas de Teópolis, pág. 16), para quem "el matrimonio sin el adulterio seria insoportable, es su unica excusa"; de Camilo Castelo Branco, segundo o qual "o adultério é a razão insurgida contra o absurdo do vínculo indissolú- 
vel"; e de Novicow (A Emancipação da Mulher, pág. 115), para o qual é o adultério "o fundamento da tranqüilidade dos lares".

Mais recentemente, nos Velhos Marinheiros, pág. 114. Jorge Amado vislumbra no adultério "pequena contrafação da rígida moral", enquanto outros procuram romanescamente fixá-lo como "cilada do destino", ou "acidente imprevisivel na vida de uma criatura" e que NaPoleấo resumiu numa frase candente: "c'est un affaire de canapé".

5. Ao direito e à moral repugna fundamentalmente essa visão materialista, tanto que a lei civil não hesita em incluir o adultério entre as causas que autorizam o desquite, mencionando-o mesmo em primeiro lugar, tal a gravidade de que se reveste (artigo $317, \mathrm{n}^{\circ} \mathrm{I}$ ). Por outro lado, coerente com a mesma ordem de idéias, a lei proibe o reconhecimento do filho adulterino, salvo depois de dissolvida a sociedade conjugal (Lei n. ${ }^{\circ} 883$, de 21-10-49, artigo $1 .^{\circ}$ ).

A lei penal, por sua vez, reprime o adultério como delito contra a família, cominando-lhe as sanções a que se refere o artigo 240 do Código Penal, embora! como anota Francisco Delgado Irribaren (El Divorcio, pág. 203), a tendência dos modernos penalistas seja a de suprimi-lo como delito, por se tratar de crime privado, cujo dano não envolve desordem social, nem problema penal político. Em sua tese de doutoramento $D a$ Incriminação do Adultério, RicArdo Antunes Andreucci faz interessante análise dêsse aspecto da questão (Capítulo IV).

6. Em face da lei, basta uma única transgressão do dever de fidelidade, quer por parte do marido, quer por parte da mulher, para que. se configure o adultério.

$O$ conceito dos clássicos de que o adultério do marido só se caracteriza com a existência de concubina teúda $\mathrm{e}$ manteúda não é mais aceito no domínio da lei civil. 
Nesse sentido, existe decisão do Tribunal de Justiça de São Paulo, estampada na Revista dos Tribunais, 180/221.

Sob êsse ângulo, os dois cônjuges se encontram no mesmo plano de igualdade. A situação de ambos é idêntica. Qual dêles espezinhe o dever de fidelidade se tornará culpado aos olhos de Deus e da religião.

De fato, um marido infiel faz à mulher a injúria mais atroz 'e causa aos filhos dano irreparável. Mas, disse São PAUlo: - sanctificatus est vir infidelis per mulierem fidelem (a mulher fiel salvará o marido infiel).

De modo idêntico, atroz é igualmente a infidelidade na mulher. De acôrdo com imagem de BALzAc, esta é, na mulher, o que a incredulidade é no sacerdote: o último têrmo da maldade humana, o maior crime, porque implica todos os outros.

7. Todavia, nem sempre se trataram as duas infrações da mesma maneira. $O$ direito romano, por exemplo, estabelecia diferenças. Segundo a lei justiniana, o adultério da mulher sempre era causa de divórcio, mas a mulher não podia invocar o adultério do marido para dissolver o matrimônio. Além disso, o adultério da mulher era severamente punido, ao passo que o do marido só se tornava culpável se praticado com mulher casada.

Penas bastante graves se previam no Fuero Juzgo, ou lex wisigothorum, e que foi o código geral de tôda a peninsula ibérica e constituíu parte do direito espanhol até começos do Século XIX. 0 mesmo sucedia na Lei das Sete Partidas, outro documento dos mais antigos da primitiva legislação espanhola, cujo autor foi Afonso IX. Por igual, as velhas Ordenações reprimiam o adultério da mulher com maior severidade, o mesmo vindo a acontecer com o Código Criminal do Império.

Hoje, porém, do ponto de vista puramente jurídico, nenhuma discriminação se pode estabelecer. As infra- 
ções de um e de outra são tratadas no mesmo pé de igualdade.

8. De um ângulo intimista, porém, o adultério da mulher é bem bais grave. Velha indulgência se incrustrou na sociedade, em relação aos deslizes do marido.

Essa indulgência parte do pressuposto de que a infidelidade no homem em regra è fruto de capricho passageiro ou de um arrebatamento momentâneo, que, de modo algum, afeta seu amor pela espôsa, enquanto o adultério desta vem demonstrar que se acham definitivamente rotos os laços afetivos em relação ao marido e assim irremediàvelmente comprometida a estabilidade do lar.

Referida tese tem sido abordada, por mais de uma vez, na literatura. Assim, escreveu Somerset Madgham que uma ligação passageira, para o homem, não tem significação sentimental, ao passo que pāra a mulher tem. Colette Yver, em seu livro - Les Dames du Palais, pág. 116, diz que a mulher que se entrega, entrega também seu pudor, sua honra, sua reputação, e tudo isso deixa subentendido o inteiro abandono de si própria.

Demais disso, os filhos adulterinos que a mulher casada venha a conceber poderão ficar a cargo do marido, o que agrava a imoralidade da situação, enquanto os do marido com a amante, que não seja casada, jamais estarão a cargo de um inocente.

Por outras palavras, o adultério da mulher tranfere para o marido, em tese, o encargo de manter prole alheia, ao passo que não terá essa conseqüência o adultério do marido. Como se expressa a sabedoria popular, o homem deixa o pecado na soleira da porta, a mulher o traz para dentro de casa.

Do ponto de vista jurídico, porém, como do ponto de vista moral, não há diferença entre os dois atos. Ambos atentam contra a lei, a moral e a religião. Ambos 
dissolvem o casamento e desagregam a família. Ambos merecem idêntica reprovação.

9. O dever de fidelidade perdura enquanto subsista a sociedade conjugal. Terminada esta, porém, pela morte, anulação do matrimonio ou desquite, readquire o cônjuge, juridicamente, plena liberdade sexual.

Se os cônjuges se mantêm apenas separados de fato, sem dissolução da sociedade conjugal, persiste a obrigação, cuja intransigente observância consagrou PenḱloPe e deu origem ao chamado complexo de Ulisses.

Contudo, já decidiu o Tribunal de Justiça do Estado que "o cônjuge que se vê obrigado a deixar o lar conjugal, por imposição do outro, deixará de lhe dever fidelidade", tendo ajuntado ainda que "descabe alegação de adultério, em desquite, se a falta ocorrera posteriormente à separação do casal" (Revista dos Tribunais, $381 / 100$ ).

Infelizmente, deterioram-se cada vez mais os valôres morais na sociedade contemporânea. Põe-se cada vez mais de lado a hipocrisia que encerra, para ver-se apenas uma expressão a mais da liberdade sexual, em que se empenha boa parte do gênero humano, como sinal de evolução e de cultura.

Comenta Pontes de Miranda (Tratado de Direito de Família, 3. ${ }^{\mathrm{a}}$ ed., 2/28), que ao dever jurídico de fidelidade corresponde o dever moral de evitar atos que possam induzir suspeita de violação do dever jurídico; mas a figura do adultério, no direito, limita-se à copula carnalis. Contudo, tem decidido o Tribunal de Justiça do Estado que procede de modo leviano e legitima a decretação de desquite por injúria grave a mulher que, no recesso de seu lar e na ausência do marido, recebe pessoa de outro sexo e conversa com ela, a desoras (Revista dos Tribunais, 382/188). E ainda que "constitui injúria grave ao marido a vivência injustificada da mulher fora do lar, em 
estreito contacto com a família de seu suposto amante" (mesma Revista, 381/157).

10. O segundo dever comum é o de vida em comum, no domicílio conjugal (artigo 231, n. ${ }^{\circ}$ II). Sem essa convivência entre os cônjuges, não existe um lar, apto a abrigar a família. A vida em comum, proclama Laurent (Principes de Droit Civil, 3/79) é um dever para os cônjuges, aliás de ordem pública, pois não existe casamento, se não maị existe vida em comum. Todavia, em Ma non é una cosa seria, de·Pirandello, há um cidadão que se casa exatamente pela vantagem de não ter de ficar com a mulher.

A infração dêsse dever, por parte do marido ou da mulher, desde que o afastamento do lar se prolongue por mais de dois anos e seja malicioso, autoriza a terminação da sociedade conjugal pelo desquite (artigo 317, n. ${ }^{\circ}$ IV).

Se o abandono se deve à mulher e é maliciosa a desertio, perde ela o direito de alimentos, cessando para o marido a obrigação de sustentá-la (artigo 234).

Igualmente, se a mulher não convivia com o marido, ao tempo da morte dêste, não lhe cabe o cargo de cabeça-de-casal, salvo prova de que essa convivência se tornou impossivel sem culpa dela (artigo 1579, § $1 .^{\circ}$ ). Idêntica restrição e com a mesma ressalva ocorre quanto às funções de inventariante (Código de Processo Civil. artigo $469, \mathrm{n}^{\circ} \mathrm{I}$ ).

Advirta-se que ao marido não assiste direito de recorrer à fôrça policial para coagir a mulher a volver à habitação, de que se afastara. $O$ emprêgo de meios coercitivos para atingir êsse objetivo deve ser excluído de modo absoluto. Não se compadece com a respeitabilidade do lar, nem com a dignidade da mulher, recondução desta, manu militari, ao domicílio comum. Conte-se primeiro com a consciência do próprio dever do que com o uso da violência para chegar a tal resultado. 
De resto, a lei mostrar-se-ia ineficaz, se pretendesse, $\dot{a}$ outrance, sustentar a situação. Na primeira oportunidade, a mulher desertaria de nôvo.

o mais que o marido pode tentar, em semelhante conjuntura, será dirigir interpelação à mulher, com ela instando para que torne ao lar. Compeli-la, porém, por meios violentos e vexatórios, ad instar do que ocorreu nos primeiros tempos de aplicação do Código Napoleão, é inadmissível perante o nosso direito.

Prevê a lei vida em comum, no domícilio conjugal. Entretanto, várias vêzes, desaparece a possibilidade de semelhante convívio, sem que se dê violação do questionado dever. E o que sucede no caso de determinadas profissões (viajante, marítimo, ocupação em outra localidade), e ainda no caso de segregação compulsórìa (prisão, exílio, doença).

Vê-se, portanto, que absoluto não é o dever de vida em comum. Embora esta constitua a regra, exceções existem, que não acarretam, de modo algum, a quebra do dever, mesmo porque, nos exemplos apontados, , continua a reinar entre os cônjuges a mesma união e a família permanece coesa.

Cessa o dever de vida em comum, desde que haja justa causa. Assim, se o marido não trata a mulher com o devido respeito, não é esta obrigada a suportar dòcilmente os atentados cometidos à sua dignidade. Aplica-se, nesse caso, o princípio comum a todos os contratos. Não pode o primeiro exigir da segunda o cumprimento de sua obrigação, a permanência no lar, se êle não cumpre a própria.

Não pode pretender o marido, outrossim, que a mulher o acompanhe na sua vida errante, sem parada, de cidade em cidade, como não pode impor-lhe a fuga ou a imigração para subtrair-se a uma condenação criminal. 
11. Cabe acrescentar ainda que autores existem sustentando que a literalidade da lei encerra eufemismo, pois o legislador quis referir-se, de modo específico, às relações sexuais entre os cônjuges.

Carvalho Santos (Código Civil Interpretado, 4/333) adere a êsse ponto de vista e assevera que o dever de coabitação não atinge sua plenitude com a simples morada debaixo do mesmo teto, tornando-se necessária, para completá-la, a satisfação do debitum conjugale.

Usada essa expressão por SÃo Paulo pela primeira vez, na Epístola aos Coríntios $(7,3)$, ela é jurìdicamente exata e traduz a principal prestação de um a outro cônjuge.

É o assunto de tal delicadeża que SANTo Afonso DE Liguori declarou que sôbre êle escrevia de joelhos. Nenhum dos cônjuges pode deliberadamente abster-se, a menos que obtenha o consentimento do outro. Acêrca dêsse tema, escreveu Olavo Pereira um belo livro: Marcoré.

A recusa injustificada pode constituir injúria grave, causa de terminação da sociedade conjugal, nos têrmos do artigo 317, n. ${ }^{\circ}$ III, do Código Civil (Revista dos Tribunais $32 / 313$ ).

12. Com as palavras mútua assistência, constantes do artigo 231, n. $^{\circ}$ III, quis o Código deixar acentuado que os cônjuges recìprocamente se obrigam à prestação de socorro material e moral. No expressivo dizer de JeMolo (Il Matrimonio, pág. 267) ai reside o elemento espiritual, que rege e vivifica o vínculo e lhe confere altíssimo valor ético.

Realmente, uma das finalidades do casamento é precisamento o mutuum adjutorium nos momentos felizes, como nos instante de adversidade. Como diz Martinho GARCEZ (Direito de Familia, pág. 241), é justamente nos revezes da sorte, na contingência da vida, nas tristes 
provações da fortuna, é nesse momento que o cônjuge é chamado a compartilhar das agruras do companheiro desgraçado, dispensando-lhe afeição, coragem, e assim exercendo a mais nobre e a mais santa das missões conjugais.

Por mais grave que seja, por exemplo, a moléstia que acometa um dos cônjuges, por mais prolongado que se mostre o mal, cabe ao outro, por solidariedade, sublimando-se no infortúnio, prestar-lhe a assistência de que seja capaz. O Papa Alexandre III levou tão longe êsse dever que chegou a decretar, como regra geral, não se separassem os consortes, ainda que um dêles viesse a tornar-se leproso.

Além dêsse confôrto moral, cabe ainda aos dois cônjuges mútua colaboração material, destacando-se, nesse aspecto, a obrigação alimentar. Aliás, no têma dos alimentos, bem maior se torna a responsabilidade do marido, pois, cabe-lhe proteger a mulher, tê-la junto de si. e subministrar-lhe tudo quanto preciso para a satisfação das necessidades do lar.

Idêntica obrigação compete também à mulher, desde que conte com recursos hábeis, e não possa o marido, por qualquer circunstância, cuidar de si próprio (Lei $n^{\circ} 4.121$, de 27-8-1963, artigo $2^{\circ}$ ).

A obrigação alimentar do marido apenas cessa, quando a mulher, sem motivo justo, abandona a habitação conjugal e a ela recusa voltar (Código Civil, artigo 234). De acôrdo ainda com a Lei n. $^{\circ} 3.807$, de 26-8-1960, artigo 14, não terá direito à obtenção dos benefícios previdenciários a mulher que se encontre na situação prevista no citado artigo 234. Até mesmo depois do desquite judicial subsistirá o encargo alimentar em relação à mulher, desde que inocente e pobre (artigo 320 ).

Ainda não é tudo. Num processo, o cônjuge há de contar com a indispensável solidariedade do outro. Do mesmo modo, numa campanha eleitoral. 
Afiança Martinho Garcez (Ob. e loc. cit.) que ocioso se revela o preceito do artigo $231, \mathbf{n}^{\circ}$ III, já que a mútua assistência é mais de fôro íntimo do que de direito. No seu entender, o cônjuge não pode ser compelido a praticar tal ação, que depende, tão-sòmente, da nobreza de seus sentimentos.

De fato, no que tange à falta de assistência moral, inexiste sanção, embora a omissão possa eventualmente configurar injúria grave, sabido que tôda infração séria aos deveres conjugais constitui grave injúria (Revista dos Tribunais, 380/164).

No tocante, porém, à falta de assistência material, pode ocorrer o delito de abandono material da família, reprimido pelo artigo 244 do Código Penal, com a redação que lhe deu a recente Lei $\mathrm{n}^{\circ}$ 5.478, de 25-7-1968, artigo 21.)

Ajunte-se ainda que o Tribunal de Justiça do Estado, no acórdão inserto na Revista dos Tribunais, 349/154, decidiu que "o abandono moral e material da família, pelo seu chefe, caracteriza a injúria e justifica o desquite pela espôsa".

13. Depois dos deveres dos cônjuges entre si, especificados nos incisos I a III, passa o Código a dispor acêrca dos deveres dêles em relação à prole, adstringindo-os ao sustento, guarda e educação dos filhos (n. ${ }^{\circ}$ IV).

Na feliz expressão de Rocco, no círculo da comunidade familiar, modelam os pais a alma do filho, do futuro cidadão. Segundo o ambiente do lar, a planta do homem crescerá, para o bem ou para o mal.

Como ensina Pontes de Miranda (Ob. cit. 2/31), o sustento compreende a subministração de alimentos, daquilo que serve para a mantença: a guarda e o cuidado, o amparo, a vigilância e a proteção; e a educação, física e moral, a que tôda pessoa tem direito, prepara o destino da criatura.

Nenhuma dessas promessas é vã. Sanciona-as o direito positivo. Na órbita penal, com a previsão dos crimes 
contra a assistência familiar (Código Penal, artigos 244 a 247).

Na órbita civil, contempla o legislador a suspensão do pátrio poder (Código Civil, artigo 394), além da privação (artigo 395, n. $^{\circ}$ II).

De modo idêntico, o Código de Menores contém várias medidas tutelares e protetoras.

A lei civil provê ainda a respeito da proteçã்o da pessoa dos filhos (artigos 325 a 329), e, no caso de desquite amigável, existe a disposição de ordem pública do artigo 642, $\mathrm{n}^{\circ} \mathrm{IV}$, do Código de Processo Civil.

É irrenunciável o direito a alimentos. Cuida-se de dever de que ninguém pode se liberar por sua exclusiva vontade.

Por fim, os pais podem confiar a guarda a outrem, ou internar os filhos em pensionatos ou estabelecimentos de educação. A precaridade da sustentação, por ausência de recursos, não induz qualquer falta (Revista de Jurisprudência do Estado da Guanabara, 12/303).

14. Eis aí, em rápidas palavras, o que nos cabe dizer sôbre os deveres comuns a ambos os cônjuges, matéria a respeito da qual pràticamente se acham acordes tôdas as legislações.

Com essas prescrições, crê o legislador poder assegurar a estabilidade da família, cuja coesão, no entanto, mais que da lei, depende da união de sentimentos e do amor.

Como diz Fornari (Dell'Obligo degli Alimenti, pág. $\mathrm{xxv}$ ), quando adolescentes, a família educa nosso coração; quando adultos, ela vem a ser a escola de moral, afastandonos das más ações pelo exemplo dos pais e pela honra de ser casado, a que acresce a fôrça do trabalho; quando velhos, ela impõe a obrigação dos bons exemplos, a fim de que nossos descendentes se tornem melhores do que nós. 